\title{
IncRNA CASC9 positively regulates CHK1 to promote breast cancer cell proliferation and survival through sponging the miR-195/497 cluster
}

\author{
GUOLI SHAO $^{1}$, MENGCHUAN WANG $^{2}$, XULONG FAN $^{3}$, LIN ZHONG $^{1}$, \\ ZIXIANG WANG ${ }^{2}$, PUSHENG ZHANG ${ }^{2}$ and SHUFENG JI ${ }^{1}$ \\ ${ }^{1}$ Specialized Medical Service Center; ${ }^{2}$ Department of General Surgery, \\ Zhujiang Hospital, Southern Medical University, Guangzhou, Guangdong 510282; \\ ${ }^{3}$ Maternity and Children's Healthcare Hospital of Foshan, Foshan, Guangdong 52800, P.R. China
}

Received January 12, 2018; Accepted August 7, 2018

DOI: $10.3892 /$ ijo.2019.4734

\begin{abstract}
Accumulating evidence has demonstrated that long non-coding RNAs (lncRNAs) play important roles in the pathogenesis and development of diverse types of human disorders. Cancer susceptibility candidate 9 (CASC9), a gene encoding a lncRNA, has frequently been reported to be dysregulated and has been implicated in multiple types of human malignancies. However, the biological role of lncRNA CASC9 in breast cancer (BC) remains largely unknown. The present study aimed to investigate the role of lncRNA CASC9 in $\mathrm{BC}$ and to elucidate the potential molecular mechanisms involved. In the present study, 1ncRNA CASC9 was found to be significantly upregulated in both BC tissues and cell lines. Furthermore, functional analyses revealed that lncRNA CASC9 accelerated BC cell proliferation, promoted cell cycle progression and suppressed cell apoptosis. Moreover, mechanical experiments demonstrated that lncRNA CASC9 positively regulated checkpoint kinase 1 (CHK1) by competitively binding to the miR-195/497 cluster in BC cells. Additionally, the knockdown of lncRNA CASC9 was observed to suppress breast tumor growth in vivo. Taken together, the results of this study indicate that IncRNA CASC9 plays an oncogenic role in BC through sponging the miR-195/497 cluster, and that IncRNA CASC9 may be used as a novel therapeutic target and as a potential diagnostic marker for $\mathrm{BC}$.
\end{abstract}

\section{Introduction}

Breast cancer $(\mathrm{BC})$, one of the most prevalent gynecological malignancies, is the second-leading cause of cancer-related

Correspondence to: Dr Shufeng Ji, Specialized Medical Service Center, Zhujiang Hospital, Southern Medical University, 253 Gongye Road, Guangzhou, Guangdong 510282, P.R. China

E-mail: sfji1211@sina.com

Key words: long non-coding RNA cancer susceptibility candidate 9, checkpoint kinase 1, breast cancer, miR-195/497 cluster mortality among women worldwide (1-3). It is documented that 246,660 new cases of BC were diagnosed and 40,450 patients succumbed to the disease in the United States in 2016 (4). Approximately 1.7 million women are estimated to be diagnosed with $\mathrm{BC}$ annually worldwide, resulting in 522,000 deaths (5). The lack of curative therapeutic strategies and drug resistance may be partially responsible for the high mortality rate associated with $\mathrm{BC}(6,7)$. Despite great progress being made in the diagnosis and treatment of $\mathrm{BC}$ over the past several decades $(1,2,6,7)$, the long-term prognosis for patients with $\mathrm{BC}$ remains unfavorable. Hence, there is an urgent need for the development of effective therapeutic alternatives for $\mathrm{BC}$ and for the identification of sensitive biomarkers for $\mathrm{BC}$ prognosis.

Long non-coding RNAs (lncRNAs) are a large group of RNA transcripts $>200$ nucleotides in length, which do not act as templates for protein synthesis $(8,9)$. IncRNAs have recently emerged as crucial players in the tumorigenesis and progression of various human cancers (10-13). Increasing evidence has indicated that lncRNAs may function as microRNA (miRNA or $\mathrm{miR}$ ) sponges to carry out their role in carcinogenesis (14-16). Cancer susceptibility candidate 9 (CASC9) is a gene located at chromosome 8q21.1, encoding a lncRNA $(17,18)$. IncRNA CASC9 has been reported to play a role in multiple types of human tumors, including gastric cancer, esophageal squamous cell carcinoma and nasopharyngeal cancer (18-20); however, little is known about its biological role in BC.

It has been well-documented that the miR-195/497 cluster belongs to the miR-15/16/195/424/497 family (miR-15 family) located at human chromosome 17p13.1 (21,22). miR-195 and miR-497, two members of the miR-15 family, are closely linked in the genome and share the same 3 ' untranslated region (3'UTR) binding seed sequence $(23,24)$. The miR-195/497 cluster has frequently been reported to be involved in a wide range of human neoplasms, such as hepatocellular carcinoma, bladder cancer and breast cancer (25-27).

This study aimed to explore the biological role of lncRNA CASC9 in BC and to elucidate the molecular mechanisms involved. IncRNA CASC9 was found to be significantly upregulated in both BC tissues and cell lines. Functional 
analyses demonstrated that lncRNACASC9 accelerated BC cell proliferation, promoted cell cycle progression and suppressed cell apoptosis. Furthermore, mechanical experiments revealed that lncRNA CASC9 played an oncogenic role in BC through sponging the miR-195/497 cluster.

\section{Materials and methods}

Patients and tissue specimens. BC tissues and matched adjacent non-cancerous tissues were obtained from 17 patients at Zhujiang Hospital (Guangzhou, China) from January, 2013 to November, 2015. Matched adjacent normal tissues were obtained at a distance of $5 \mathrm{~cm}$ from the BC tissues. All clinical specimens were immediately frozen in liquid nitrogen and stored at $-80^{\circ} \mathrm{C}$ for further analyses. This study was carried out in accordance with the guidelines by the Ethics and Scientific Committee of Southern Medical University (Guangzhou, China). Written informed consent was obtained from all patients enrolled in the current study.

Cell culture. One normal human breast epithelial cell line (MCF-10A) and four BC cell lines (MDA-MB-231, MDA-MB-468, MCF7 and MDA-MB-415) were obtained from the Shanghai Cell Bank, Chinese Academy of Sciences (Shanghai, China). These cells were cultured in Dulbecco's modified Eagle's medium (DMEM; Gibco-BRL, Grand Island, New York, NY, USA) supplemented with $10 \%$ fetal bovine serum (FBS, Sigma-Aldrich, St. Louis, MO, USA). All the cells were maintained at $37^{\circ} \mathrm{C}$ in a humidified incubator with $5 \% \mathrm{CO}_{2}$.

$R N A$ extraction and reverse transcription-quantitative PCR $(R T-q P C R)$. Total RNA and miRNAs were extracted from the tissues and cells using TRIzol reagent (Qiagen, Hilden, Germany) according to the manufacturer's instructions. Following quantification with a Nanodrop 2000 spectrophotometer (Thermo Fisher Scientific, Waltham, MA, USA), the extracted total RNA was reverse transcribed using a Reverse Transcription kit (Takara, Dalian, China). Quantitative PCR (qPCR) was performed on an Applied Biosystems 7500 Fast Real-Time PCR system (Applied Biosystems, Foster City, CA, USA). The specific primer sequences synthesized by Shanghai Sangon Biological Engineering Technology \& Services Co., Ltd. (Shanghai, China) and were as follows: CASC9 forward, 5'-AGATGAAGCCGGTACCTCAGAT-3' and reverse, 5'-TCA CTTTAAAGAGGGAGAGGAG-3'; checkpoint kinase 1 (CHK1) forward, 5'-CAGAATTTCAACCTTCGGTGTG-3' and reverse, 5'-TCTTCACTGCGACTGCTTCTTC-3'; and GAPDH forward, 5'-ACAACTTTGGTATCGTGGAAGG-3' and reverse, 5'-GCCATCACGCCACAGTTTC-3'. The PCR conditions were as follows: denaturation at $95^{\circ} \mathrm{C}$ for $10 \mathrm{~min}$, followed by 40 cycles of $95^{\circ} \mathrm{C}$ for $5 \mathrm{sec}$ and $60^{\circ} \mathrm{C}$ for $40 \mathrm{sec}$. GAPDH was used as an endogenous control to normalize the lncRNA CASC9 and CHK1 expression levels. The relative expression level was calculated using the $2^{-\Delta \Delta \mathrm{Cq}}$ method (28). The experiments were performed in triplicate.

Cell transfection. Cell transfection was performed using Lipofectamine 2000 (Invitrogen/Thermo Fisher Scientific) according to the manufacturer's instructions. The cells (5x $10^{5}$ cells/ well in 6-well plates, $70-80 \%$ confluency) were transfected with CASC9 mimics or si-CASC9. CASC9 mimics and small interfering RNA to knockdown CASC9 were synthesized by Shanghai GenePharma Co., Ltd. (Shanghai, China). Small interfering RNA sequences are listed as follows: si-CASC9 sense, 5'-TGTAAACTATAAAAATAAGC-3' and si-CASC9 antisense, 5'-GCTTATTTTTATAGTTTACA-3'; and si-NC sense, ACAGGAGACAAATAAGCAT and antisense, ATGCTTATTTGTCTCCTGT. miR-195 inhibitor and miR-497 inhibitor were also designed by Shanghai GenePharma Co., Ltd. and used for the downregulation of miR-195 and miR-497, respectively. The sequences of miR-195 inhibitor and miR-497 inhibitor were as follows: miR-195 inhibitor, 5'-GCCAAUAUUUCUGUGCUGCUA-3'; miR-497 inhibitor, 5'-ACAAACCACAGUGUGCUGCUG-3'. The cells were harvested at $48 \mathrm{~h}$ post-transfection for use in further experiments.

Cell viability assay. Cell proliferation was assessed using the MTT Cell Proliferation and Cytotoxicity Assay kit (Sigma-Aldrich) according to the manufacturer's instructions. In brief, the cells were seeded in each well of a 96-well plate at a density of $1 \times 10^{4}$ cells/ well. Following incubation at $37^{\circ} \mathrm{C}$ for different periods of time $(0,24,48$ and $72 \mathrm{~h})$, the culture medium was removed and MTT $(20 \mu \mathrm{l} ; 5 \mathrm{mg} / \mathrm{ml})$ was added to each well. Following incubation at $37^{\circ} \mathrm{C}$ for a further $4 \mathrm{~h}$, the MTT solution was removed and replaced with dimethyl sulfoxide (DMSO; $150 \mu \mathrm{l}, 4 \%$; Sigma-Aldrich). The absorbance was measured at $560 \mathrm{~nm}$ using a microplate reader (BioTek Instruments GmbH, Bad Friedrichshall, Germany).

Cell apoptosis assay. For apoptosis analysis, the cells were harvested at $48 \mathrm{~h}$ post-transfection. The cells were washed with ice-cold PBS and stained with Annexin V-fluorescein isothiocyanate (FITC) apoptosis detection kits (BD Biosciences, San Diego, CA, USA). The stained cells were measured using a flow cytometer (BD Biosciences).

RNA-binding protein immunoprecipitation. RIP assays were performed using the EZ-Magna RIP ${ }^{\mathrm{TM}}$ RNA-Binding Protein Immunoprecipitation kit (Millipore, Billerica, MA, USA) according to the manufacturer's instructions. Briefly, RIP buffer containing magnetic beads conjugated with human anti-Ago2 antibody (1:500; 03-110; Millipore) or negative control IgG (1:500; ab172730; Abcam, Cambridge, MA, USA) was added to cell lysate and incubated overnight at $4^{\circ} \mathrm{C}$. Proteinase $\mathrm{K}$ was used to digest the protein and the co-precipitated RNAs were then isolated. The purified RNAs were subjected to RT-qPCR analysis.

Bioinformatics analysis. miRanda algorithms were used to predict the potential targets of IncRNA CASC9 and miR-197/495.

Luciferase reporter assay. Wild-type IncRNA-CASC9 and mutant lncRNA CASC9 were inserted into pmirGLO reporter vectors (Promega, Madison, WI, USA), respectively. The MDA-MB-231 cells were co-transfected with miR-195 mimics and wild-type lncRNA CASC9 or mutant lncRNA CASC9 using Lipofectamine 2000 (Invitrogen/Thermo Fisher 
Scientific). The relative luciferase activity was measured on a dual-luciferase reporter assay system (Promega) at $48 \mathrm{~h}$ post-transfection. Data were expressed as the ratio of Renilla luciferase activity to Firefly luciferase activity. Luciferase reporter assays to validate the binding of miR-497 to lncRNA CASC9 were performed as described above.

Western blot analysis. Protein lysates were extracted from the cells using $500 \mu 1$ radio immunoprecipitation assay (RIPA) buffer with $1 \mathrm{mM}$ phenylmethane sulfonyl fluoride. The samples were subsequently sonicated for $2 \mathrm{~min}$ and centrifuged at $12,000 \mathrm{x}$. The supernatants were collected and used for protein analysis. Protein concentrations were determined by BCA. Lysates $(10 \mu \mathrm{l})$ were separated on $8 \%$ polyacrylamide gels and transferred onto PVDF membranes. The membranes were blocked with phosphate-buffered saline (PBS) containing $0.1 \%$ Tween-20 (PBST) and 5\% non-fat milk $(\mathrm{w} / \mathrm{v})$ for $1 \mathrm{~h}$ at room temperature. After they were washed with PBST, the membranes were probed with the primary antibodies overnight at $4^{\circ} \mathrm{C}$. The primary antibodies were as follows: Anti-CHK1 (ab40866), anti-cyclin D1 (CCND1; ab134175), anti-cyclin-dependent kinase 4 (CDK4; ab108357), anti-B-cell lymphoma 2 (Bcl2; ab32124), anti-caspase-3 (ab13585) and anti-GAPDH (ab181602) and were obtained from Abcam and used at the following dilutions: anti-CHK1 (1:1,000), anti-CCND1 (1:1,000), anti-CDK4 (1:1,000), anti-Bcl2 $(1: 1,000)$, anti-caspase-3 $(1: 1,000)$ and anti-GAPDH $(1: 3,000)$. The membranes were washed again with PBST, then horseradish peroxidase (HRP) labeled IgG (1:500; ab6728; Abcam) at a 1:5,000 dilution was added at room temperature for $1 \mathrm{~h}$, and the blots were developed using ECL Western blotting reagents. Western blots were quantified by densitometry with Labworks 4.0 Software (UVP BioImaging Systems, Upland, CA, USA).

Xenograft tumor model assay. All animal experiments were performed in accordance with institutional and international animal regulations. The animal experimental protocol was approved by the Animal Care and Use Committee of Southern Medical University. Female BALB/c nude mice (6 weeks of age, weighing approximately $18 \mathrm{~g}$ ) were purchased from Beijing HFK Bioscience Co., Ltd. (Beijing, China). Mice had ad libitum access to food and water. The MDA-MB-415 cells transfected with si-NC or si-CASC $9\left(1 \times 10^{6}\right.$ cells per mouse) were subcutaneously injected into the flanks of the BALB/c nude mice, respectively. The length and width of the tumors were measured using a caliper every 5 days. All the mice were euthanized using 4-5\% isoflurane and sacrificed in a $\mathrm{CO}_{2}$ chamber (flow rate of $\mathrm{CO}_{2}, 20 \%$ chamber volume per minute) at day 35 post-injection. The tumor nodules of the mice were then removed and weighed. The tumor volume was calculated according to the following equation: Tumor volume $\left(\mathrm{mm}^{3}\right)=$ length $(\mathrm{mm}) \mathrm{x}$ width $(\mathrm{mm})^{2} / 2$.

Immunohistochemistry. The samples were fixed in $10 \%$ neutral buffered formalin, embedded in paraffin, and sliced into thin sections ( $5 \mu \mathrm{m}$ thickness). After being dewaxed and rehydrated, the sections were incubated with $3 \% \mathrm{H}_{2} \mathrm{O}_{2}$ for 30 min to block the endogenous peroxidase (POD) activity. Following antigen retrieval (AR) by microwave (heating), 5\% bovine serum albumin (BSA) was applied to block non-specific binding. The sections were then incubated with the primary antibodies at $4^{\circ} \mathrm{C}$ overnight. Anti-Ki67 (ab15580) and anti-GAPDH (ab181602) were obtained from Abcam and used at the following dilutions: anti-Ki67 $(1: 1,000)$ and anti-GAPDH (1:3,000). After being rinsed with PBS 3 times for 5 min each, the sections were treated with biotinylated secondary antibody (1:200; ab6728; Abcam) for $1 \mathrm{~h}$, followed by incubation with streptavidin-horseradish peroxidase (HRP) at $37^{\circ} \mathrm{C}$ for $20 \mathrm{~min}$. Diaminobenzidine (DAB) substrate was used as a color developing agent for the visualization of Ki67-positive cells.

In situhybridization (ISH). The tissue slides were pre-hybridized in a hybridization solution (Boster Bioengineering Co., Ltd., Wuhan, China) at $37^{\circ} \mathrm{C}$ for $2 \mathrm{~h}$. Subsequently, 10 picomoles of digoxigenin-labeled detection probes (Boster Bioengineering Co., Ltd.) complementary to lncRNA CASC9 were added and hybridized overnight at $37^{\circ} \mathrm{C}$. Following stringent washes, an immunological reaction was carried out using a mouse monoclonal antibody to digoxigenin (1:200; ab6212; Abcam;), followed by the addition of alkaline phosphatase-conjugated streptavidin dilution (BD Biosciences) to detect the streptavidin dilution probes. The slides were mounted with aqueous mounting medium (Maixin Biotechnology, Fuzhou, China).

TUNEL staining. Apoptosis assay was performed using an In Situ Cell Death Detection kit (Roche Diagnostics, Basel, Switzerland). Briefly, the sections were blocked by incubation in $3 \% \mathrm{H}_{2} \mathrm{O}_{2}$ in methanol for $5 \mathrm{~min}$ at $25^{\circ} \mathrm{C}$. Subsequently, the sections were labeled with $\mathrm{TdT}$ labeling reaction mix at $37^{\circ} \mathrm{C}$ for $1 \mathrm{~h}$. Nuclei exhibiting DNA fragmentation were visualized by incubation in 3,3'-diaminobenzidine (DAB) for $15 \mathrm{~min}$ at $25^{\circ} \mathrm{C}$. The sections were observed under a light microscope (BX51; Olympus, Tokyo, Japan) and photographed.

Statistical analysis. Data are presented as the means \pm standard deviation (SD). Statistical analysis was performed using SPSS 16.0 software (SPSS, Chicago, IL, USA). Two-tailed Student's t-test was applied to compare the differences between 2 groups and one-way analysis of variance (ANOVA) followed by Dunnett's multiple comparison was employed to compare the differences among 3 independent groups. The correlation between IncRNA CASC9 expression and miR-195, miR-497 or CHK1 mRNA expression in the BC tissues was identified using Pearson's correlation analysis. A value of $\mathrm{P}<0.05$ was considered to indicate a statistically significant difference.

\section{Results}

lncRNA CASC9 is significantly upregulated in BC tissues and cell lines. Although CASC9 has been reported to play a role in the carcinogenesis and progression of multiple types of human malignancies, its biological roles in $\mathrm{BC}$ remain poorly understood. In this study, initially, we carried out RT-qPCR analysis to detect the expression of lncRNA CASC9 in 17 pairs of $\mathrm{BC}$ tissues and corresponding para-cancerous tissues. As presented in Fig. 1A, lncRNA CASC9 expression was significantly upregulated in the $\mathrm{BC}$ tissues compared with the matched adjacent normal tissues $(\mathrm{P}<0.01)$. To further investigate the differences in IncRNA CASC9 expression between 
A

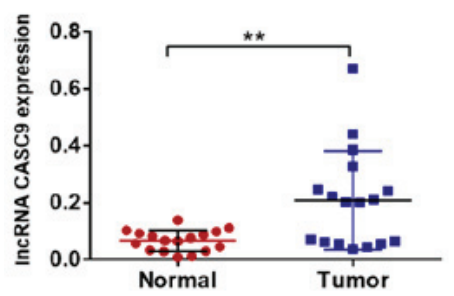

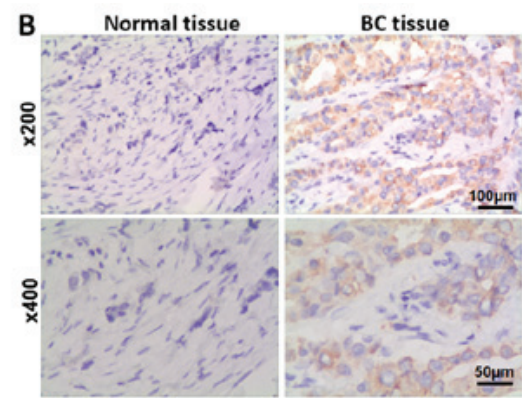

C

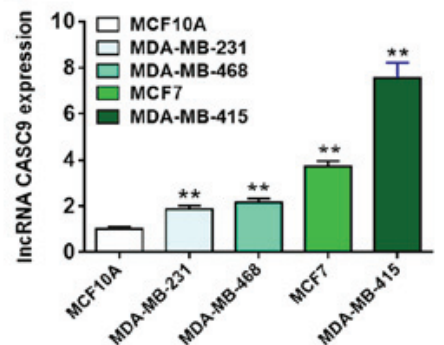

Figure 1. IncRNA CASC9 expression is significantly upregulated in BC tissues and cell lines. (A) Relative expression levels of lncRNA CASC9 in 17 pairs of $\mathrm{BC}$ tissues and corresponding para-cancerous tissues were detected by RT-qPCR analysis. ${ }^{* *} \mathrm{P}<0.01$. (B) IncRNA CASC9 expression in BC tissues and matched normal tissues of patients was visualized by ISH. (C) Relative expression levels of lncRNA CASC9 in one normal human breast epithelial cell line (MCF-10A) and four BC cell lines (MDA-MB-231, MDA-MB-468, MCF7 and MDA-MB-415). ${ }^{* *} \mathrm{P}<0.01$ vs. normal cell line. lncRNA CASC9, long non-coding RNA cancer susceptibility candidate 9; BC, breast cancer; ISH, in situ hybridization.
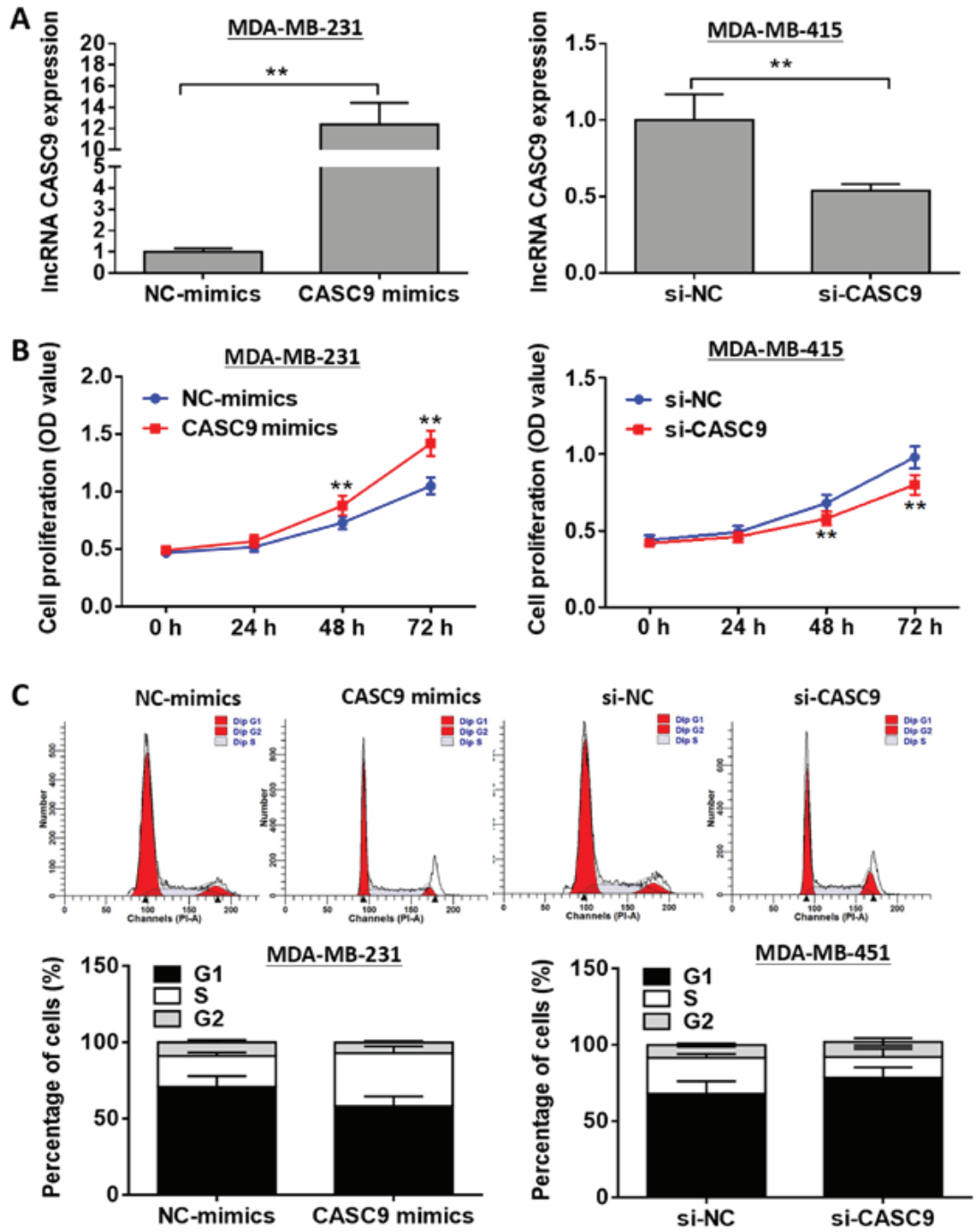

Figure 2. Effects of CASC9 on BC cell proliferation and cell cycle. (A) Relative expression levels of lncRNA CASC9 were assessed by RT-qPCR following transfection with CASC9 mimics or si-CASC9. (B) Cell proliferation was evaluated by MTT assay following transfection with CASC9 mimics or si-CASC9. (C) Cell cycle was analyzed by flow cytometry following transfection with CASC9 mimics or si-CASC9. ${ }^{* *} \mathrm{P}<0.01$ vs. NC. CASC9, cancer susceptibility candidate 9; $\mathrm{BC}$, breast cancer; $\mathrm{NC}$, negative control.

the $\mathrm{BC}$ tissues and their matched non-cancerous tissues, we performed ISH analysis to visualize the expression of lncRNA CASC9. As shown by ISH analysis, the BC tissues exhibited higher expression levels of IncRNA CASC9 than the matched non-cancerous tissues (Fig. 1B). Consistently, lncRNA CASC9 expression was markedly upregulated in the BC cell lines (MDA-MB-231, MDA-MB-468, MCF7 and MDA-MB-415) compared with the normal human mammary epithelial 
A MDA-MB-231

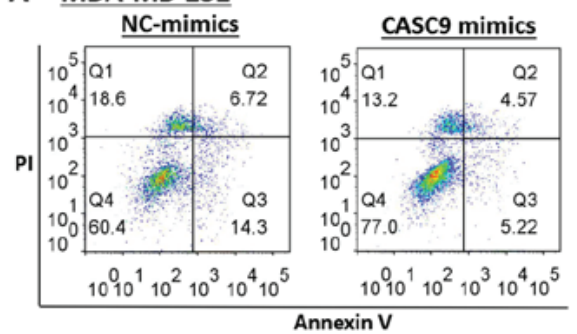

B MDA-MB-415

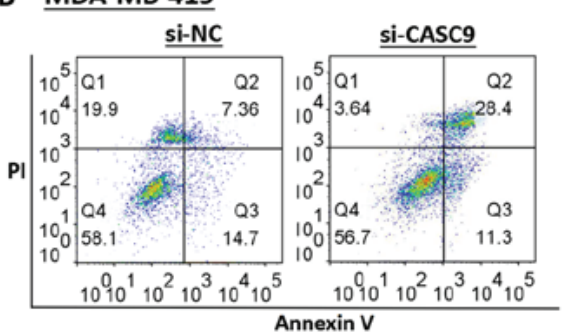

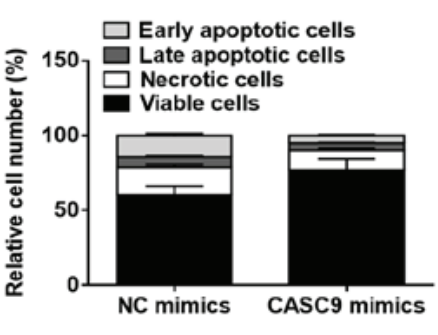
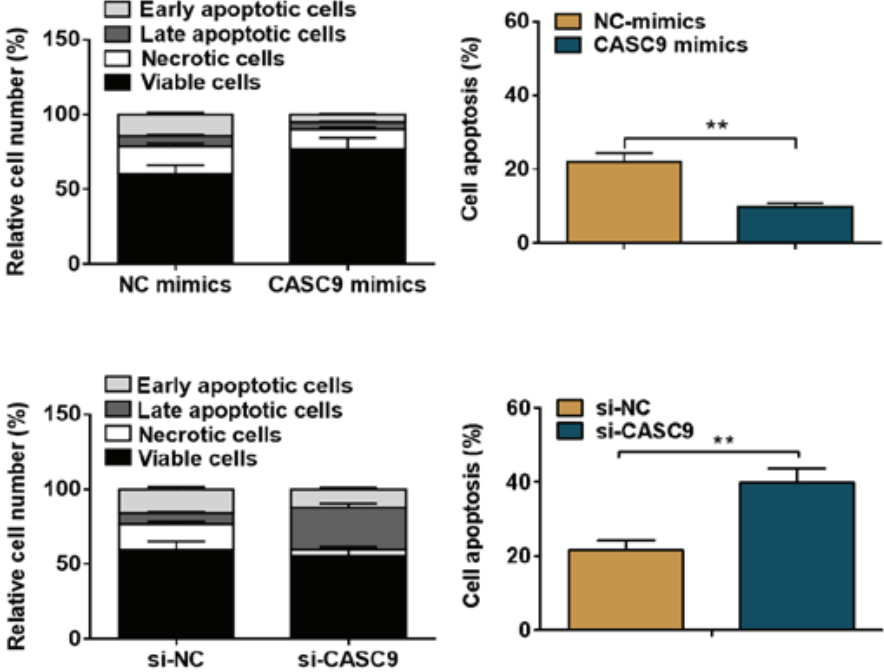

Figure 3. Effects of CASC9 on BC cell apoptosis. (A) Cell apoptosis was evaluated by flow cytometry following transfection with NC-mimics or CASC9 mimics. (B) Cell apoptosis was evaluated by flow cytometry following transfection with si-NC or si-CASC9. Upper left quadrant represents necrotic cells, lower left quadrant represents viable cells, upper right quadrant represents late apoptotic cells, and lower right quadrant represents early apoptotic cells. ${ }^{* * *} \mathrm{P}<0.01$. CASC9, cancer susceptibility candidate 9; BC, breast cancer; NC, negative control.

cell line, MCF-10A ( $\mathrm{P}<0.01$, Fig. 1C). The MDA-MB-231 cells (lowest endogenous IncRNA CASC9 expression) were selected for overexpression experiments. The MDA-MB-415 cells (highest endogenous IncRNA CASC9 expression) were selected for knockdown experiments. Taken together, these findings indicated that IncRNA CASC9 expression was significantly upregulated in the $\mathrm{BC}$ tissues and cell lines.

CASC9 promotes BC cell proliferation and inhibits apoptosis. To explore the biological role of CASC9 in BC, overexpression experiments were conducted using the MDA-MB-231 cells. In addition, knockdown experiments were performed using the MDA-MB-415 cells. The transfection efficiency was determined by RT-qPCR analysis (Fig. 2A). As shown by the results of MTT assays, MDA-MB-231 cell proliferation was markedly accelerated by transfection with CASC 9 mimics compared with the negative control group, whereas CASC9 knockdown markedly attenuated MDA-MB-415 cell proliferation $(\mathrm{P}<0.01$; Fig. 2B). As shown in Fig. 2C, transfection with CASC9 mimics promoted MDA-MB-231 cell cycle progression, while cell cycle arrest was observed in the MDA-MB-415 cells transfected with si-CASC9 $(\mathrm{P}<0.01)$. Additionally, CASC9 overexpression was found to markedly suppress MDA-MB-231 cell apoptosis compared with the negative control group, whereas MDA-MB-415 cell apoptosis was significantly promoted by CASC9 knockdown ( $\mathrm{P}<0.01$; Fig. 3).

In addition, we examined the effects of IncRNA CASC9 on the expression of cell proliferation-associated proteins and apoptosis-associated proteins in the BC cells. Lower expression levels of CCND1, CDK4 and Bcl2, and a higher expression level of caspase-3 were observed in the MDA-MB-231 cells transfected with CASC9 mimics compared with the negative control group $(\mathrm{P}<0.01$; Fig. $4 \mathrm{~A})$, whereas CASC9 knockdown was found to elevate the expression levels of CCND1, CDK4 and Bcl2, and to decrease the expression of caspase- 3 in comparison with the
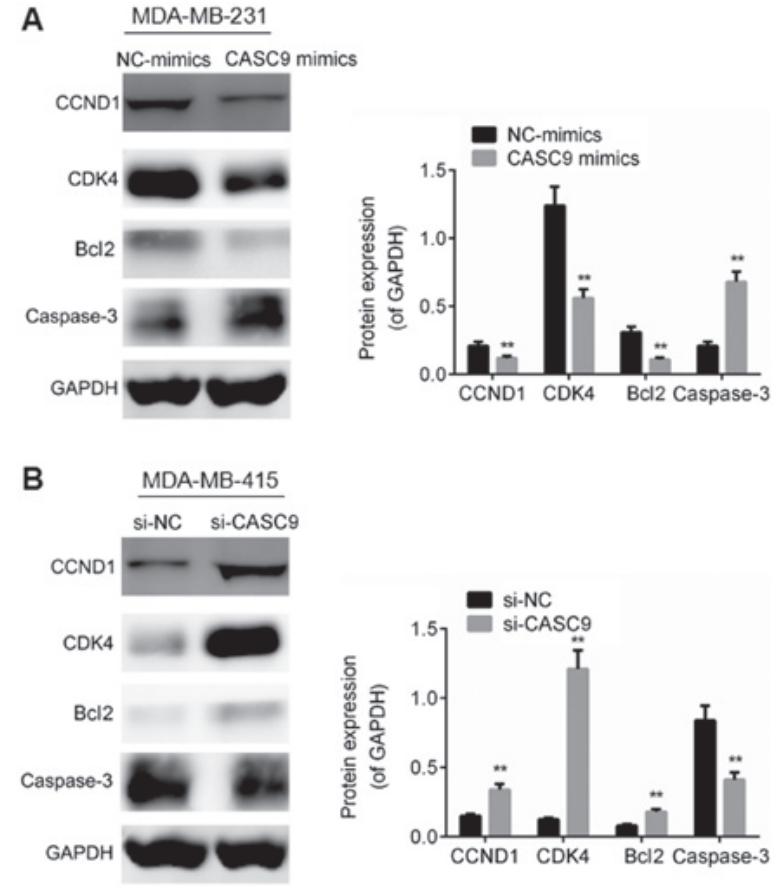

Figure 4. CASC9 regulates the expression of cell proliferation-associated proteins and apoptosis-associated proteins in BC cells. (A) The expression of cell proliferation-associated proteins and apoptosis-associated proteins was examined by western blot analysis in the MDA-MB-231 cells following transfection with NC-mimics or CASC9 mimics. (B) The expression of cell proliferation-associated proteins and apoptosis-associated proteins was evaluated by western blot analysis in MDA-MB-415 cells following transfection with si-NC or si-CASC9. ${ }^{* *} \mathrm{P}<0.01$. CASC9, cancer susceptibility candidate 9 ; $\mathrm{NC}$, negative control; CCND1, cyclin D1; CDK4, cyclin-dependent kinase 1; Bcl2, B-cell lymphoma 2.

negative control group ( $\mathrm{P}<0.01$; Fig. 4B). On the whole, these results suggest that CASC9 facilitates BC cell proliferation, accelerates cell cycle progression and suppresses cell apoptosis. 
A CASC9 5'...AUgGacaCAUUUGCUGCUU

| | ||| ||

miR-195 3'...UUUGGUGUCACACGACGAC miR-497 3'...GUUAUAAAGACACGACGAU
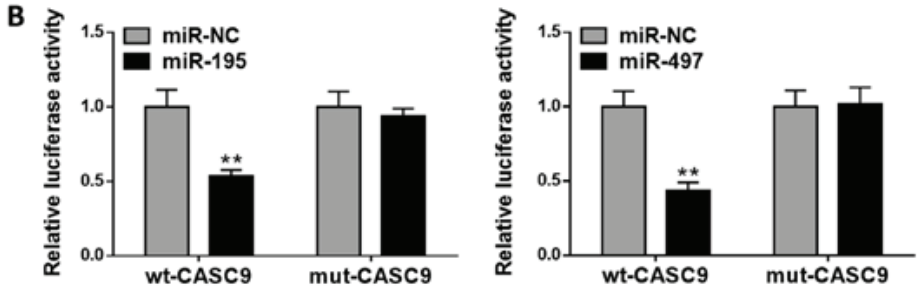

C
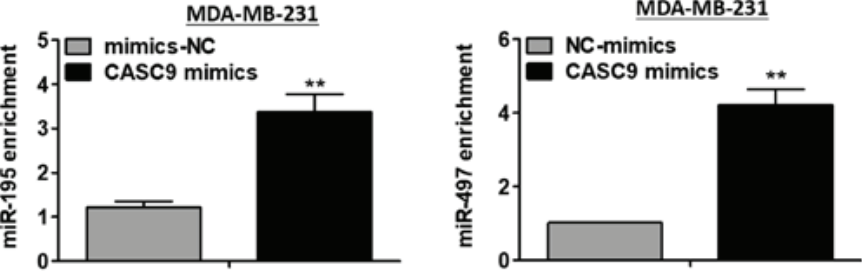

Figure 5. CASC9 interacts with the miR-195/497 cluster in BC cells. (A) A putative binding site of miR-195/497 cluster in CASC9 was predicted using the miRanda algorithm. (B) Luciferase activity was identified following co-transfection with miR-195/497 and wt-CASC9 or mut-CASC9. (C) Anti-Ago2 RIP was performed to enrich miRNAs interacting with CASC9 in MDA-MB-231 cells following transfection with mimics-NC or CASC9 mimics, followed by RT-qPCR to detect miR-195/miR-497 expression levels in the immunoprecipitates. ${ }^{* *} \mathrm{P}<0.01$ vs. NC. CASC9, cancer susceptibility candidate 9 ; BC, breast cancer; wt, wild-type; mut, mutant; Ago2, argonaute 2, RIP, RNA immunoprecipitation.
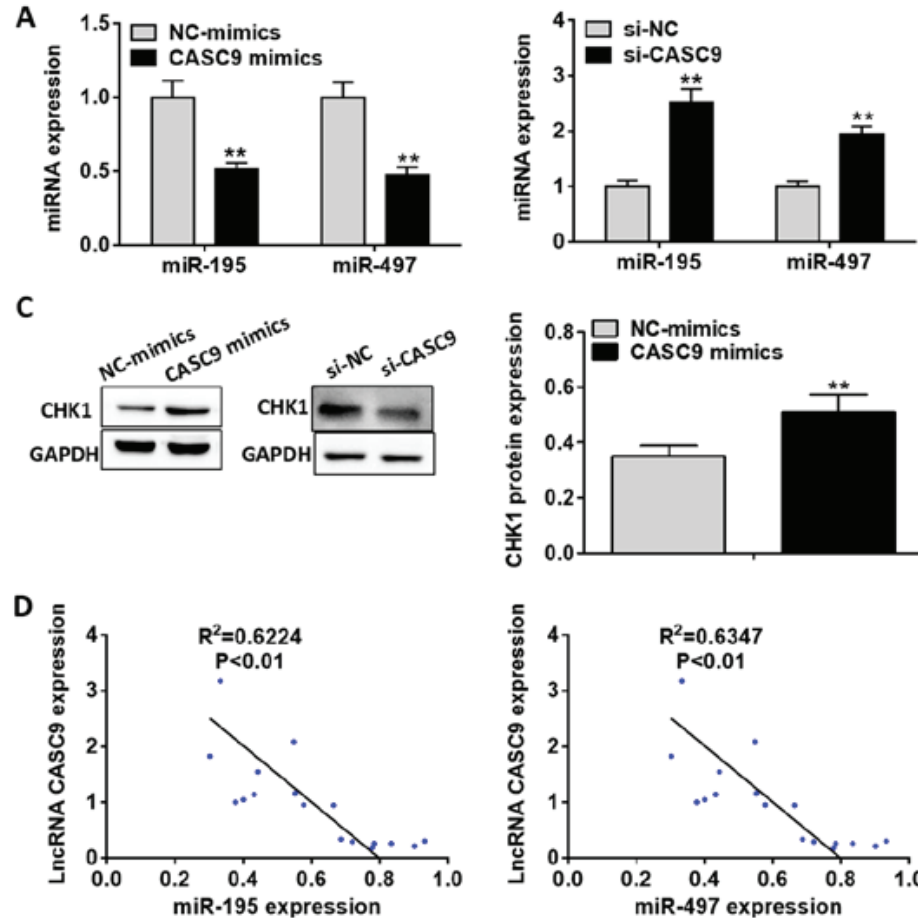

B

CHKI 5'... CUAACUAUUCUGCUGCUA

I I III II

miR-195 $3^{\prime}$...UUUGGUGUCACACGACGAC miR-497 3'...GUUAUAAAGACACGACGAU
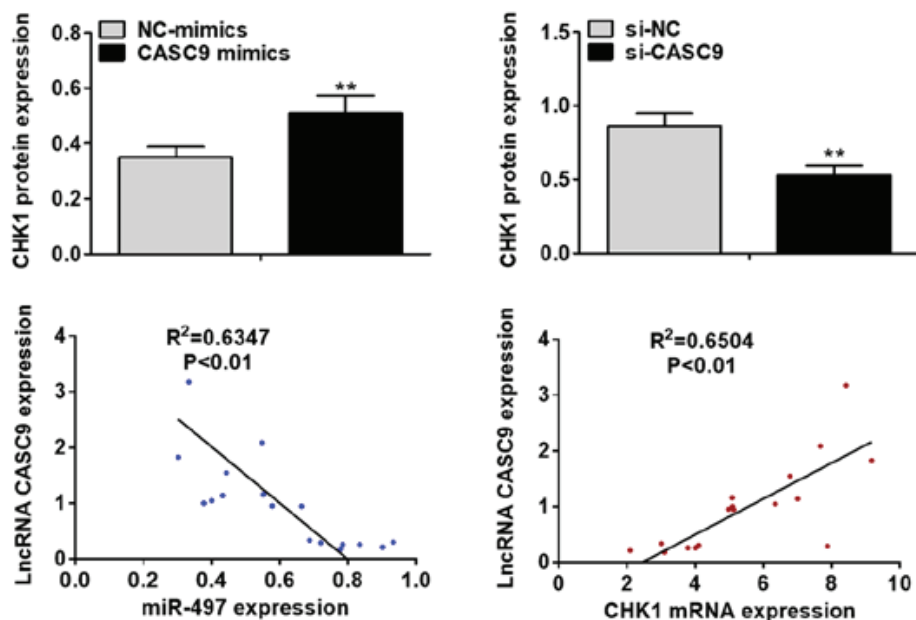

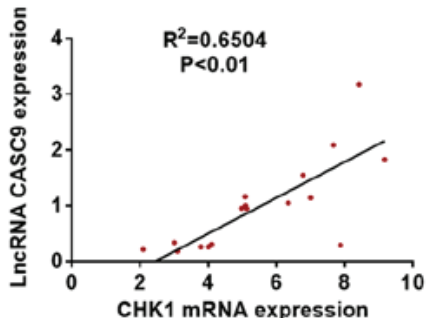

Figure 6. CASC9 positively regulates CHK1 expression by sponging the miR-195/497 cluster in BC cells. (A) miRNA expression was analyzed using RT-qPCR following transfection with CASC9 mimics or si-CASC9. (B) A putative binding site of the miR-195/497 cluster in CHK1 3'UTR was predicted by miRanda online software. (C) The protein expression of CHK1 was examined by western blot analysis following transfection with CASC9 mimics or si-CASC9. (D) Correlation between CASC9 expression and miR-195, miR-497 or CHK1 mRNA expression in BC tissues of patients was determined by Pearson's correlation analysis. ${ }^{* *} \mathrm{P}<0.01$ vs. NC. CASC9, cancer susceptibility candidate 9; BC, breast cancer; CHK1, checkpoint kinase 1 ; 3'UTR, $3^{\prime}$ untranslated region; $\mathrm{NC}$, negative control.

CASC9 directly interacts with the miR-195/497 cluster in BC cells. Recent studies have suggested that lncRNAs function as miRNA sponges to participate in the occurrence and development of multiple types of human neoplasms $(29,30)$. To elucidate the underlying mechanisms through which lncRNA
CASC9 facilitates BC cell proliferation and suppresses cell apoptosis, we applied miRanda online software to predict the potential targets of IncRNA CASC9. The miR-195/497 cluster, frequently reported to be involved in diverse types of human tumors, was selected as a candidate target of IncRNA CASC9 


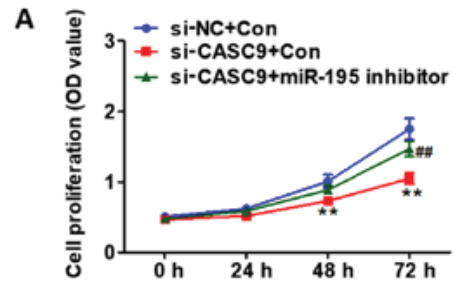

B

$\mathrm{Pl}$

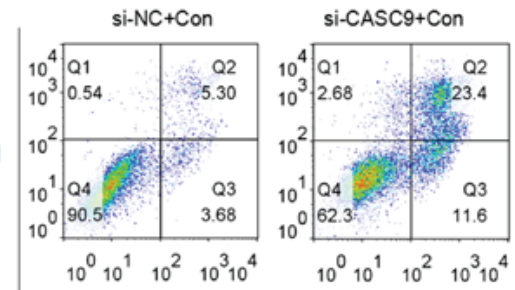

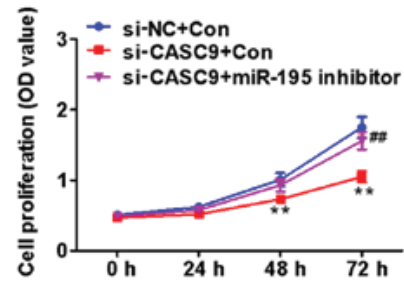

si-CASC9+miR-195 inhibitor si-CASC9+miR-497 inhibitor

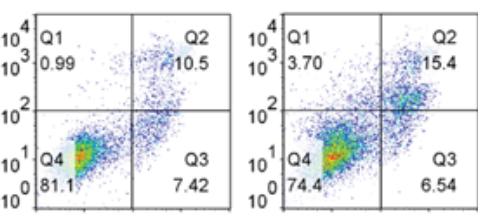

$\begin{array}{lllll}10^{0} 10^{1} & 10^{2} & 10^{3} 10^{4} & 10^{0} 10^{1} \quad 10^{2} \quad 10^{3} 10^{4}\end{array}$
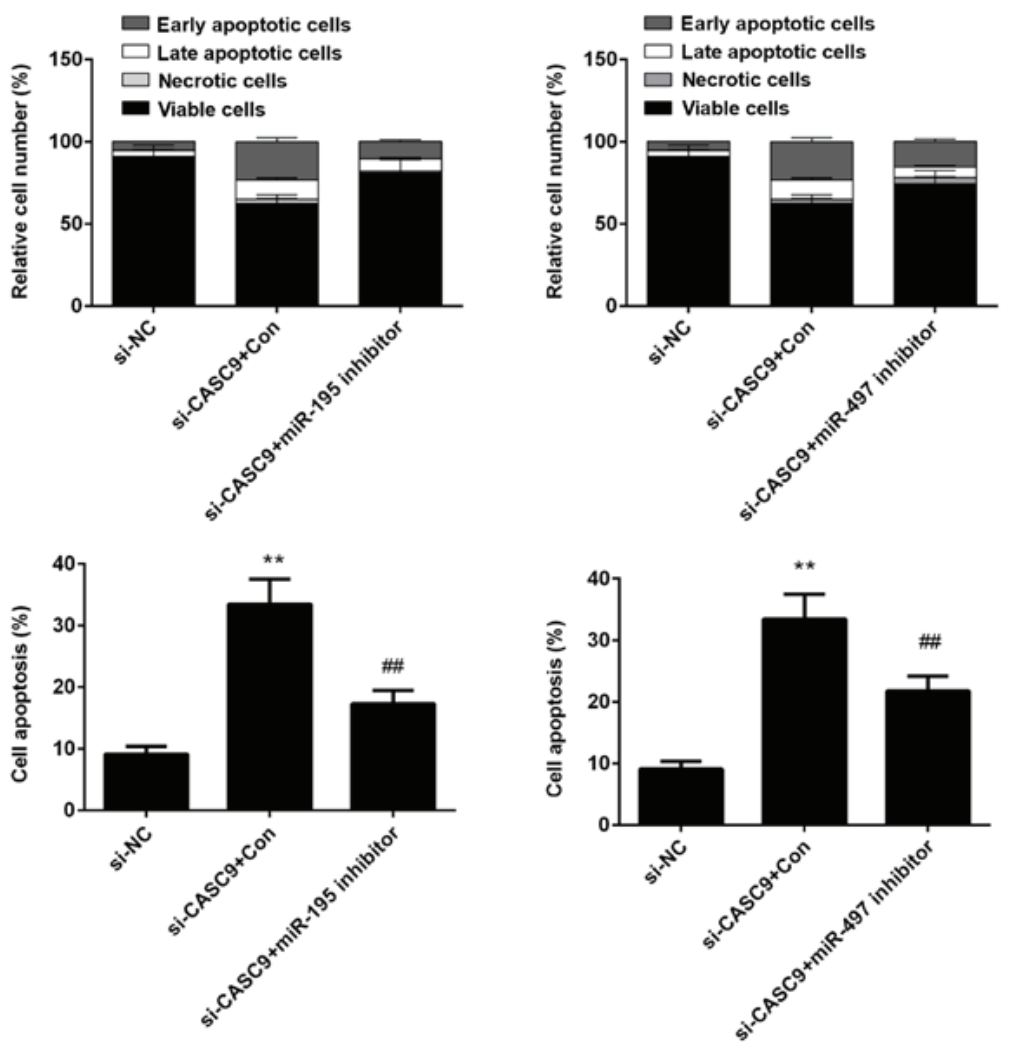

Figure 7. miR-195 or miR-497 downregulation attenuates the inhibitory effects of CASC9 knockdown on BC cell proliferation and apoptosis. (A) Cell proliferation was evaluated by MTT assays after the downregulation of the expression of miR-195 or miR-497. (B) Cell apoptosis was assessed using flow cytometry after the downregulation of the expression of miR-195 or miR-497. In the flow cytometry, plots, the upper left quadrant represents necrotic cells, lower left quadrant represents viable cells, upper right quadrant represents late apoptotic cells, and the lower right quadrant represents early apoptotic cells. ${ }^{* *} \mathrm{P}<0.01$ vs. si-NC; ${ }^{\# P} \mathrm{P}<0.01$ vs. siCASC9 + miR-195/497 inhibitor. CASC9, cancer susceptibility candidate 9; BC, breast cancer; NC, negative control.

(Fig. 5A). Moreover, we constructed luciferase reporter vectors carrying the predicted miR-195/497 binding site (wild-type IncRNA CASC9) or its corresponding mutant fragment (mutant lncRNA CASC9). As illustrated in Fig. 5B, the co-transfection of wide-type lncRNA CASC9 and miR-195 or miR-497 markedly reduced the luciferase activity, while the co-transfection of mutant lncRNA CASC9 and miR-195 or miR-497 failed to affect the luciferase activity $(\mathrm{P}<0.01)$. To validate the interaction between lncRNA CASC9 and the miR-195/497 cluster, anti-Ago2 RIP assays were carried out to pull down the endogenous miRNAs interacting with lncRNA
CASC9 in the MDA-MB-231 cells. miR-195 and miR-497 were found to be notably enriched by lncRNA CASC 9 mimics in comparison with the negative control group $(\mathrm{P}<0.01$; Fig. 5C). These data indicate that lncRNA CASC9 interacts with the miR-195/497 cluster in BC cells.

CASC9 positively regulates $C H K 1$ expression by sponging the miR-195/497 cluster. As illustrated in Fig. 6A, miR-195 and miR-497 expression levels were found to be markedly downregulated by transfection with CASC9 mimics in the MDA-MB-231 cells compared with the negative control 

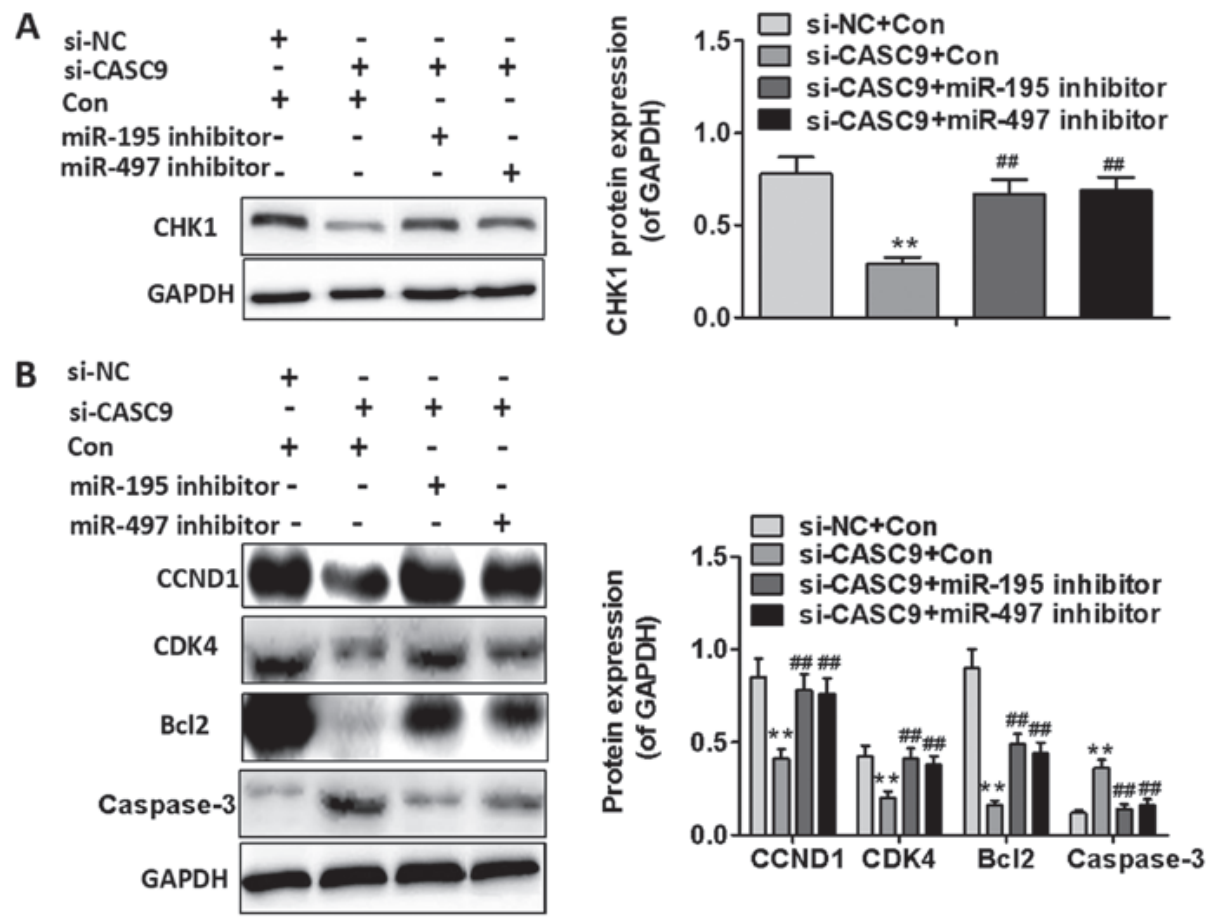

Figure 8. mR-195 or miR-497 downregulation affects the expression of cell proliferation-associated proteins and cell apoptosis-associated proteins. (A) CHK1 protein expression was determined by western blot analysis following the downregulation of miR-195 or miR-497. (B) The expression of cell proliferation-associated proteins and apoptosis-associated proteins was examined by western blot analysis following the downregulation of miR-195 or miR-497. ${ }^{* *} \mathrm{P}<0.01$ compared with si-NC group + Con; ${ }^{\# \#} \mathrm{P}<0.01$ compared with si-CASC9 + Con group. CASC9, cancer susceptibility candidate 9; CHK1, checkpoint kinase 1; NC, negative control; CCND1, cyclin D1; CDK4, cyclin-dependent kinase 1; Bcl2, B-cell lymphoma 2.

group, whereas CASC9 knockdown notably upregulated the miR-195 and miR-497 expression levels in the MDA-MB-415 cells $(\mathrm{P}<0.01)$. To further elucidate the potential mechanisms through which IncRNA CASC9 promotes BC cell proliferation and survival, the potential targets of the miR-195/497 cluster were predicted using the miRanda algorithm (Fig. 6B). Among all the putative targets of the miR-195/497 cluster, CHK1 attracted our attention for its crucial role in the tumorigenesis and progression of various types of human malignancies. A previous study identified CHK1 as a target of miR-497 in hepatocellular carcinoma (31).

To investigate whether IncRNA CASC9 regulates CHK1 expression, we transfected the BC cells with CASC 9 mimics or si-CASC9. The results of western blot analysis demonstrated that CHK1 protein expression was significantly enhanced by transfection of the MDA-MB-231 cells with CASC9 mimics compared with the negative control, whereas CASC9 knockdown was discovered to suppress CHK1 expression in the MDA-MB-415 cells ( $\mathrm{P}<0.01$; Fig. 6C). Notably, Pearson's correlation analysis revealed that IncRNA CASC9 expression negatively correlated with miR-195 and miR-497 expression in the BC tissues; on the contrary, IncRNA CASC9 expression was found to positively correlate with CHK1 mRNA expression in the $\mathrm{BC}$ tissues $(\mathrm{P}<0.01$; Fig. $6 \mathrm{D})$. These results suggest that lncRNA positively regulates the expression of CHK1 through sponging the miR-195/497 cluster in BC cells.

The miR-195/497 cluster mediates the effects of CASC9 on $B C$ cell proliferation and apoptosis. To determine whether the effects of CASC9 on BC cell proliferation and apoptosis are mediated by the miR-195/497 cluster, we downregulated the expression of miR-195 or miR-497 in the MDA-MB-415 cells transfected with si-CASC9. As shown in Fig. 7A, the inhibitory effects of CASC9 knockdown on BC cell proliferation were partially reversed by the downregulation of miR-195 or miR-497. Furthermore, miR-195 or miR-497 downregulation was found to attenuate MDA-MB-415 cell apoptosis induced by CASC9 knockdown $(\mathrm{P}<0.01$; Fig. 7B). The results of western bot analysis also revealed that the use of the miR-195 or miR-497 inhibitor significantly upregulated the expression of CHK1 in the MDA-MB-415 cells transfected with si-CASC9 ( $\mathrm{P}<0.01$; Fig. 8A). As shown in Fig. 8B, the use of the miR-195 or miR-497 inhibitor partially reversed the inhibitory effects of si-CASC9 on CCND1, CDK4 and Bcl2 expression, and attenuated the promoting effects of si-CASC9 on caspase- 3 expression in the MDA-MB-415 cells $(\mathrm{P}<0.01)$. These data indicate that the promoting effects of CASC9 on $\mathrm{BC}$ cell proliferation and survival are mediated by the miR-195/497 cluster.

Knockdown of CASC9 suppresses breast tumor growth in vivo. With the aim of investigating the effects of CASC9 on breast tumor growth in vivo, we performed tumor xenograft model assays. As presented in Fig. 9A, CASC9 knockdown markedly inhibited breast tumor growth in vivo $(\mathrm{P}<0.01)$. Immunohistochemistry revealed that Ki67 expression in the tumors removed from the nude mice was significantly suppressed in the mice injected with cells transfected with si-CASC9 compared with the mice injected with cells from the negative control group (Fig. 9B). Furthermore, TUNEL staining demonstrated that CASC9 knockdown markedly facilitated cell apoptosis in the tumors separated from the 

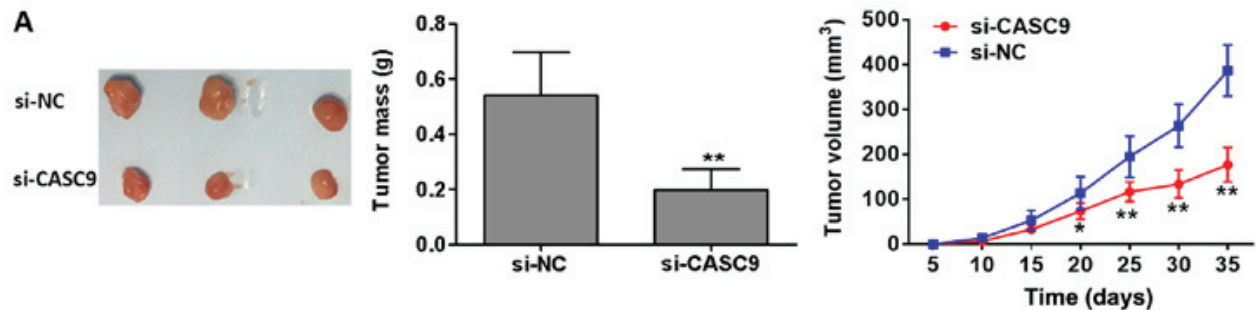

B
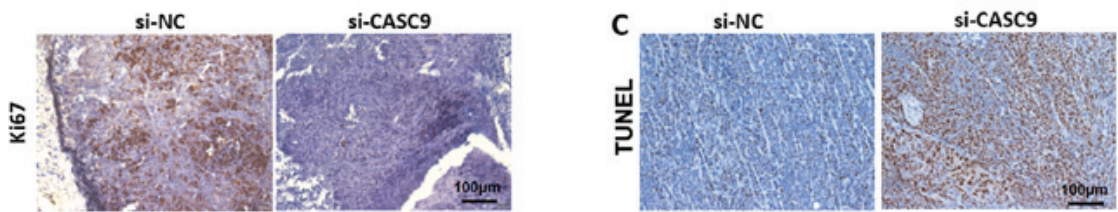

D

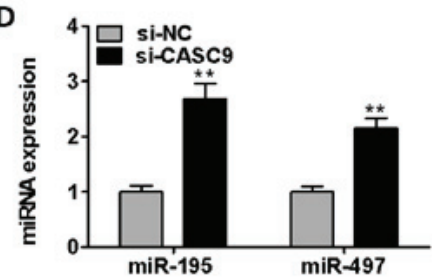

E

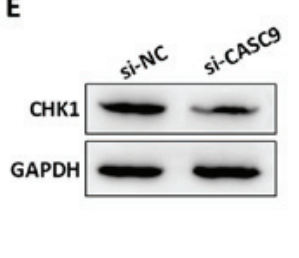

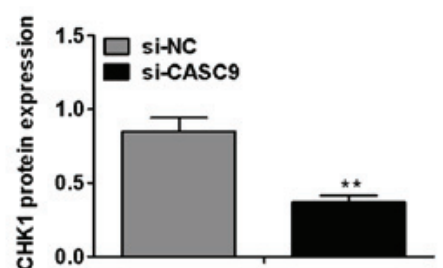

Figure 9. Knockdown of CASC9 suppresses breast tumor growth in vivo. (A) MDA-MB-415 cells transfected with si-NC or si-CASC9 were injected into the flanks of nude mice $(\mathrm{n}=3)$. The volumes of tumors $\left(\mathrm{mm}^{3}\right)$ were measured every 5 days using a slide caliper; at day 35 post-implantation, the mice were anaesthetized using 4-5\% isoflurane and sacrificed in a $\mathrm{CO}_{2}$ chamber $\left(\mathrm{CO}_{2}\right.$ flow rate, $20 \%$ chamber volume per minute). The tumors were then collected and weighed. (B) The protein expression of Ki67 in the tumors removed from nude mice was visualized by immunohistochemical staining. (C) Apoptosis in the removed tumors of nude mice was identified by TUNEL staining. (D) CHK1 mRNA expression in the tumors removed from nude mice was determined by RT-qPCR analysis. (E) CHK1 protein expression in the tumors removed from nude mice was evaluated by western blot analysis. ${ }^{* * *} \mathrm{P}<0.01 \mathrm{vs}$. si-NC. CASC9, cancer susceptibility candidate 9; BC, breast cancer; IHC, immunohistochemistry; TUNEL, terminal deoxynucleotidyl transferase-mediated nick end labeling; CHK1, checkpoint kinase 1; NC, negative control.

nude mice (Fig. 9C). Additionally, CASC9 knockdown was found to suppress CHK1 mRNA and protein expression in the separated tumors $(\mathrm{P}<0.01$; Fig. 9D and E). Taken together, these data suggest that the knockdown of CASC9 inhibits breast tumor growth in vivo.

\section{Discussion}

BC, a fatal gynecological malignancy, has imposed great pressure on woman worldwide (32). Although conventional therapeutic approaches, such as hormonal therapy, chemotherapy and surgery, have improved the overall survival of patients with $\mathrm{BC}$ to a certain extent, the long-term prognosis remains unsatisfactory. Increasing evidence has indicated that lncRNAs play crucial roles in the pathogenesis and development of a wide range of human disorders. Furthermore, previous studies have reported that the ectopic expression of lncRNA CASC9 plays a role in the oncogenesis of multiple types of human tumors. Pan et al found that lncRNA CASC9 was upregulated in esophageal cancer and exerted promoting effects on cell migration and invasion (17). It has also been demonstrated that IncRNA CASC9 is dysregulated and is involved in several human tumors. IncRNA CASC9 was discovered to be upregulated in gastric cancer and to function as an oncogene through the negative modulation of MDR1 (18). Wu et al demonstrated that lncRNA CASC9 was upregulated in esophageal squamous cell carcinoma and played an oncogenic role by negatively regulating programmed cell death 4 (PDCD4) (19). Su et al reported that lncRNA CASC9 was highly expressed in nasopharyngeal cancer and played tumor-promoting roles by stabilizing hypoxia-inducible factor $1 \alpha($ HIF $1 \alpha)(20)$. However, the role of lncRNA CASC9 remains largely unclear. Hence, a better understanding of the biological functions of 1ncRNA CASC9 in BC may be beneficial for the development of effective therapeutic alternatives and identifying valuable diagnostic markers.

In the present study, we initially analyzed the expression of lncRNA CASC9 in 17 pairs of BC tissues and adjacent non-cancerous tissues by RT-qPCR and ISH analyses. lncRNA CASC9 expression was discovered to be significantly upregulated in BC tissues. Consistently, lncRNA CASC9 expression was found to be markedly upregulated in $\mathrm{BC}$ cell lines. With an aim of obtaining a better understanding of the biological role of lncRNA CASC9 in BC, we carried out functional analyses. Functional analyses demonstrated that lncRNA CASC9 accelerated BC cell proliferation. Previous studies have demonstrated that the inhibition of apoptosis contributes to enhanced cell viability, whereas the induction of apoptosis leads to weakened cell viability (33-35). In accordance with these studies, in this study, we found that the increased cell proliferation was partially due to the inhibition of apoptosis and that the induction of apoptosis accounted for the decreased cell proliferation. In addition, transfection with IncRNA-CASC9 mimics was observed to enhance the expression of CCND1, CDK4 and $\mathrm{Bcl} 2$, and to decrease the expression of caspase-3. These findings indicate that lncRNA may function as an oncogene in $\mathrm{BC}$.

A number of studies have proposed that lncRNAs may function as ceRNAs to sequester miRNAs from their target mRNAs $(36,37)$. Previous studies have reported that 
miR-195/497 plays tumor-suppressing roles in diverse types of human cancers, including hepatocellular carcinoma, bladder cancer, breast cancer, pancreatic cancer and nasopharyngeal cancer (25-27,38-41). CHK1, an evolutionarily conserved serine/threonine protein kinase, is a key player in the checkpoint signaling response $(42,43)$. CHK1 can carry out its role by phosphorylating the crucial regulators related to cell cycle progression (44). Numerous studies have demonstrated that CHK1 functions as an oncogene in various human malignancies, including hepatocellular carcinoma, leukemia, pancreatic cancer, non-small cell lung cancer, ovarian clear cell cancer, and neuroblastoma $(31,45-49)$. In this study, to explore the underlying molecular mechanisms through which lncRNA CASC9 exerts its tumor-promoting effects in BC, bioinformatics analysis and luciferase reporter assays were carried out and the results demonstrated that lncRNA CASC9 could competitively bind to the miR-195/497 cluster in BC cells. Notably, lncRNA CASC9 was observed to positively regulate CHK1 expression by sponging the miR-195/497 cluster in BC cells. Furthermore, 1ncRNA CASC9 expression was found to inversely correlate with miR-195 and miR-497 expression, but to positively correlate with $\mathrm{CHK} 1 \mathrm{mRNA}$ expression in $\mathrm{BC}$ tissues.

To further elucidate the potential mechanisms underlying $\mathrm{BC}$ carcinogenesis and progression, we downregulated the expression of miR-195 or miR-497 in the MDA-MB-415 cells transfected with si-CASC9. miR-195 or miR-497 downregulation was observed to partially reverse the inhibitory effects of CASC9 knockdown on BC proliferation and survival. These results indicated that the effects of IncRNA CASC9 on $\mathrm{BC}$ proliferation and survival were mediated partially by the miR-195/497 cluster. Furthermore, CASC9 knockdown was found to suppress breast tumor growth in vivo.

In conclusion, IncRNA CASC9 expression was found to be significantly upregulated in both $\mathrm{BC}$ tissues and cell lines, and IncRNA CASC9 was found to function as an oncogene in BC through sponging the miR-195/497 cluster. This study may provide new insight into the understanding of the molecular mechanisms underlying BC tumorigenesis and progression. Hence, IncRNA CASC9 may be used as a valuable therapeutic target and a novel diagnostic marker for BC.

\section{Acknowledgements}

Not applicable.

\section{Funding}

No funding was received.

\section{Availability of data and materials}

All data generated or analyzed during this study are included in this published article.

\section{Authors' contributions}

All authors (GS, MW, XF, LZ, ZW, PZ and SJ) were involved in the conception and design of this study. GS, MW and XF wrote the manuscript. LZ and ZW performed the experiments.
PZ and SJ carried out the statistical analysis. All authors have read and approved the final manuscript.

\section{Ethics approval and consent to participate}

This study was carried out in accordance with the guidelines by the Ethics and Scientific Committee of Southern Medical University (Guangzhou, China). Written informed consent was obtained from all patients enrolled in the current study. All animal experiments were performed in accordance with institutional and international animal regulations. The animal experimental protocol was approved by the Animal Care and Use Committee of Southern Medical University.

\section{Patient consent for publication}

Not applicable.

\section{Competing interests}

The authors declared that they have no competing interests.

\section{References}

1. Hall IJ, Rim SH, Johnson-Turbes CA, Vanderpool R and Kamalu NN: The African American Women and Mass Media campaign: A CDC breast cancer screening project. J Womens Health (Larchmt) 21: 1107-1113, 2012.

2. Lu J, Steeg PS, Price JE, Krishnamurthy S, Mani SA, Reuben J, Cristofanilli M, Dontu G, Bidaut L, Valero V, et al: Breast cancer metastasis: Challenges and opportunities. Cancer Res 69: 4951-4953, 2009.

3. Ursini-Siegel $\mathbf{J}$ and Muller WJ: The ShcA adaptor protein is a critical regulator of breast cancer progression. Cell Cycle 7: 1936-1943, 2008.

4. Siegel RL, Miller KD and Jemal A: Cancer statistics, 2016. CA Cancer J Clin 66: 7-30, 2016.

5. Ferlay J, Soerjomataram I, Dikshit R, Eser S, Mathers C, Rebelo M, Parkin DM, Forman D and Bray F: Cancer incidence and mortality worldwide: Sources, methods and major patterns in GLOBOCAN 2012. Int J Cancer 136: E359-E386, 2015.

6. Lytle GH: Immunotherapy of breast cancer: A review of the development of cell-specific therapy. Semin Surg Oncol 7: 211-216, 1991.

7. Guerrero-Zotano A,MayerIA and ArteagaCL:PI3K/AKT/mTOR: Role in breast cancer progression, drug resistance, and treatment. Cancer Metastasis Rev 35: 515-524, 2016.

8. Jain S, Thakkar N, Chhatai J, Pal Bhadra M and Bhadra U: Long non-coding RNA: Functional agent for disease traits. RNA Biol 14: 522-535, 2017.

9. Jin G, Sun J, Isaacs SD, Wiley KE, Kim ST, Chu LW, Zhang Z, Zhao H, Zheng SL, Isaacs WB, et al: Human polymorphisms at long non-coding RNAs (lncRNAs) and association with prostate cancer risk. Carcinogenesis 32: 1655-1659, 2011.

10. Zhao J, Liu Y, Zhang W, Zhou Z, Wu J, Cui P, Zhang Y and Huang G: Long non-coding RNA Linc00152 is involved in cell cycle arrest, apoptosis, epithelial to mesenchymal transition, cell migration and invasion in gastric cancer. Cell Cycle 14: 3112-3123, 2015.

11. Shen Y, Katsaros D, Loo LW, Hernandez BY, Chong C, Canuto EM, Biglia N, Lu L, Risch H, Chu WM, et al: Prognostic and predictive values of long non-coding RNA LINC00472 in breast cancer. Oncotarget 6: 8579-8592, 2015.

12. Lu W, Zhang H, Niu Y, Wu Y, Sun W, Li H, Kong J, Ding K, Shen HM, Wu H, et al: Long non-coding RNA linc00673 regulated non-small cell lung cancer proliferation, migration, invasion and epithelial mesenchymal transition by sponging miR-150-5p. Mol Cancer 16: 118-131, 2017.

13. Zhang W, Huang C, Gong Z, Zhao Y, Tang K, Li X, Fan S, Shi L, Li X, Zhang P, et al: Expression of LINC00312, a long intergenic non-coding RNA, is negatively correlated with tumor size but positively correlated with lymph node metastasis in nasopharyngeal carcinoma. J Mol Histol 44: 545-554, 2013. 
14. Weiss $\mathrm{M}$, Plass $\mathrm{C}$ and Gerhauser C: Role of lncRNAs in prostate cancer development and progression. Biol Chem 395: 1275-1290, 2014.

15. Cui Y, Yi L, Zhao JZ and Jiang YG: Long noncoding RNA HOXA11-AS functions as miRNA sponge to promote the glioma tumorigenesis through targeting miR-140-5p. DNA Cell Biol 36 822-828, 2017.

16. Wu XS, Wang F, Li HF, Hu YP, Jiang L, Zhang F, Li ML, Wang XA, Jin YP, Zhang YJ, et al: LncRNA-PAGBC acts as a microRNA sponge and promotes gallbladder tumorigenesis. EMBO Rep 18: 1837-1853, 2017.

17. Pan Z, Mao W, Bao Y, Zhang M, Su X and Xu X: The long noncoding RNA CASC9 regulates migration and invasion in esophageal cancer. Cancer Med 5: 2442-2447, 2016.

18. Shang C, Sun L, Zhang J, Zhao B, Chen X, Xu H and Huang B: Silence of cancer susceptibility candidate 9 inhibits gastric cancer and reverses chemoresistance. Oncotarget 8: 15393-15398, 2017.

19. Wu Y, Hu L, Liang Y, Li J, Wang K, Chen X, Meng H, Guan X, Yang K and Bai Y: Up-regulation of lncRNA CASC9 promotes esophageal squamous cell carcinoma growth by negatively regulating PDCD4 expression through EZH2. Mol Cancer 16: $150-162,2017$

20. Su X, Li G and Liu W: The Long Noncoding RNA Cancer Susceptibility Candidate 9 Promotes Nasopharyngeal Carcinogenesis via Stabilizing HIF1a. DNA Cell Biol 36: 394-400, 2017.

21. Guo ST, Jiang CC, Wang GP, Li YP, Wang CY, Guo XY, Yang RH, Feng Y, Wang FH, Tseng HY, et al: MicroRNA-497 targets insulin-like growth factor 1 receptor and has a tumour suppressive role in human colorectal cancer. Oncogene 32: 1910-1920, 2013

22. Grünhagen J, Bhushan R, Degenkolbe E, Jäger M, Knaus $P$, Mundlos S, Robinson PN and Ott CE: MiR-497 195 cluster microRNAs regulate osteoblast differentiation by targeting BMP signaling. J Bone Miner Res 30: 796-808, 2015.

23. Sato T, Yamamoto T and Sehara-Fujisawa A: miR-195/497 induce postnatal quiescence of skeletal muscle stem cells. Nat Commun 5: 4597, 2014

24. Wei W, Zhang WY, Bai JB, Zhang HX, Zhao YY, Li XY and Zhao SH: The NF-кB-modulated microRNAs miR-195 and miR-497 inhibit myoblast proliferation by targeting Igf1r, Insr and cyclin genes. J Cell Sci 129: 39-50, 2016

25. Furuta M, Kozaki K, Tanimoto K, Tanaka S, Arii S, Shimamura T, Niida A, Miyano S and Inazawa J: The tumor-suppressive miR-497-195 cluster targets multiple cell-cycle regulators in hepatocellular carcinoma. PLoS One 8: e60155, 2013.

26. Itesako T, Seki N, Yoshino H, Chiyomaru T, Yamasaki T, Hidaka H, Yonezawa T, Nohata N, Kinoshita T, Nakagawa M, et al: The microRNA expression signature of bladder cancer by deep sequencing: The functional significance of the miR-195/497 cluster. PLoS One 9: e84311, 2014.

27. Li D, Zhao Y, Liu C, Chen X, Qi Y, Jiang Y, Zou C, Zhang X, Liu S, Wang X, et al: Analysis of MiR-195 and MiR-497 expression, regulation and role in breast cancer. Clin Cancer Res 17: 1722-1730, 2011.

28. Livak KJ and Schmittgen TD: Analysis of relative gene expression data using real-time quantitative PCR and the $2-\Delta \Delta C T$ method Methods 25: 402-408, 2001.

29. Shao Y, Ye M, Li Q, Sun W, Ye G, Zhang X, Yang Y, Xiao B and Guo J: LncRNA-RMRP promotes carcinogenesis by acting as a miR-206 sponge and is used as a novel biomarker for gastric cancer. Oncotarget 7: 37812-37824, 2016.

30. Yu X, Mi L, Dong J and Zou J: Long intergenic non-protein-coding RNA 1567 (LINC01567) acts as a 'sponge' against microRNA-93 in regulating the proliferation and tumorigenesis of human colon cancer stem cells. BMC Cancer 17: 716, 2017.

31. Xie Y, Wei RR, Huang GL, Zhang MY, Yuan YF and Wang HY: Checkpoint kinase 1 is negatively regulated by miR-497 in hepatocellular carcinoma. Med Oncol 31: 844-848, 2014.

32. Konecny GE: Impact of molecular breast cancer portraits on new treatment strategies for gynecologic malignancies. Curr Opin Obstet Gynecol 25: 38-39, 2013.

33. Kumi-Diaka J, Hassanhi M, Brown J, Merchant K, Garcia C and Jimenez W: CytoregR inhibits growth and proliferation of human adenocarcinoma cells via induction of apoptosis. J Carcinog 5: $1-8,2006$.
34. Prasad R, Vaid M and Katiyar SK: Grape proanthocyanidin inhibit pancreatic cancer cell growth in vitro and in vivo through induction of apoptosis and by targeting the PI3K/Akt pathway. PLoS One 7: e43064, 2012.

35. Atmaca H, Özkan AN and Zora M: Novel ferrocenyl pyrazoles inhibit breast cancer cell viability via induction of apoptosis and inhibition of PI3K/Akt and ERK1/2 signaling. Chem Biol Interact 263: 28-35, 2017.

36. Marrone AK, Beland FA and Pogribny IP: Noncoding RNA response to xenobiotic exposure: An indicator of toxicity and carcinogenicity. Expert Opin Drug Metab Toxicol 10: 1409-1422, 2014.

37. Yang S, Ning Q, Zhang G, Sun H, Wang Z and Li Y: Construction of differential mRNA-lncRNA crosstalk networks based on ceRNA hypothesis uncover key roles of lncRNAs implicated in esophageal squamous cell carcinoma. Oncotarget 7 : 85728-85740, 2016.

38. Amer M, Elhefnawi M, El-Ahwany E, Awad AF, Gawad NA, Zada S and Tawab FM: Hsa-miR-195 targets PCMT1 in hepatocellular carcinoma that increases tumor life span. Tumour Biol 35: 11301-11309, 2014.

39. Yan JJ, Zhang YN, Liao JZ, Ke KP, Chang Y, Li PY, Wang M, Lin JS and He XX: MiR-497 suppresses angiogenesis and metastasis of hepatocellular carcinoma by inhibiting VEGFA and AEG-1. Oncotarget 6: 29527-29542, 2015.

40. Xu J, Wang T, Cao Z, Huang H, Li J, Liu W, Liu S, You L, Zhou L, Zhang T, et al: MiR-497 downregulation contributes to the malignancy of pancreatic cancer and associates with a poor prognosis. Oncotarget 5: 6983-6993, 2014.

41. Wang S, Mo Y, Midorikawa K, Zhang Z, Huang G, Ma N, Zhao W, Hiraku Y, Oikawa S and Murata M: The potent tumor suppressor miR-497 inhibits cancer phenotypes in nasopharyngeal carcinoma by targeting ANLN and HSPA4L. Oncotarget 6: 35893-35907, 2015.

42. Zhao $\mathrm{H}$ and Piwnica-Worms H: ATR-mediated checkpoint pathways regulate phosphorylation and activation of human Chk1. Mol Cell Biol 21: 4129-4139, 2001.

43. Liu Q, Guntuku S, Cui XS, Matsuoka S, Cortez D, Tamai K, Luo G, Carattini-Rivera S, DeMayo F, Bradley A, et al: Chk1 is an essential kinase that is regulated by Atr and required for the G(2)/M DNA damage checkpoint. Genes Dev 14: 1448-1459, 2000.

44. Schmitt E, Boutros R, Froment C, Monsarrat B, Ducommun B and Dozier C: CHK1 phosphorylates CDC25B during the cell cycle in the absence of DNA damage. J Cell Sci 119: 4269-4275, 2006.

45. Bryant C, Scriven K and Massey AJ: Inhibition of the checkpoint kinase Chk1 induces DNA damage and cell death in human Leukemia and Lymphoma cells. Mol Cancer 13: 147-158, 2014.

46. Parsels LA, Morgan MA, Tanska DM, Parsels JD, Palmer BD, Booth RJ, Denny WA, Canman CE, Kraker AJ, Lawrence TS, et al: Gemcitabine sensitization by checkpoint kinase 1 inhibition correlates with inhibition of a $\operatorname{Rad} 51$ DNA damage response in pancreatic cancer cells. Mol Cancer Ther 8: 45-54, 2009.

47. Grabauskiene S, Bergeron EJ, Chen G, Thomas DG, Giordano TJ, Beer DG, Morgan MA and Reddy RM: Checkpoint kinase 1 protein expression indicates sensitization to therapy by checkpoint kinase 1 inhibition in non-small cell lung cancer. J Surg Res 187: 6-13, 2014.

48. Itamochi H, Nishimura M, Oumi N, Kato M, Oishi T, Shimada M, Sato S, Naniwa J, Sato S, Kudoh A, et al: Checkpoint kinase inhibitor AZD7762 overcomes cisplatin resistance in clear cell carcinoma of the ovary. Int J Gynecol Cancer 24: 61-69, 2014

49. Cole KA, Huggins J, Laquaglia M, Hulderman CE, Russell MR, Bosse K, Diskin SJ, Attiyeh EF, Sennett R, Norris G, et al: RNAi screen of the protein kinome identifies checkpoint kinase 1 (CHK1) as a therapeutic target in neuroblastoma. Proc Natl Acad Sci USA 108: 3336-3341, 2011.

This work is licensed under a Creative Commons Attribution-NonCommercial-NoDerivatives 4.0 International (CC BY-NC-ND 4.0) License. 